\title{
Comparative Study on Particles Formation in a Diesel Engine When Lubricating Oil Involved in Fuel Combustion
}

\author{
Lihui Dong, ${ }^{1}$ Weiqiang Han, ${ }^{2}$ Xingyu Liang, ${ }^{3}$ and Yuesen Wang ${ }^{3}$ \\ ${ }^{1}$ School of Aeronautical Engineering, Civil Aviation University of China, Tianjin 300300, China \\ ${ }^{2}$ Laboratory of IC Engine, Xihua University, Chengdu 610039, China \\ ${ }^{3}$ State Key Laboratory of Engines, Tianjin University, No. 92 Weijin Road, Nankai District, Tianjin 300072, China
}

Correspondence should be addressed to Xingyu Liang; tjulxy@163.com

Received 18 January 2015; Accepted 23 February 2015

Academic Editor: Ming Huo

Copyright (C) 2015 Lihui Dong et al. This is an open access article distributed under the Creative Commons Attribution License, which permits unrestricted use, distribution, and reproduction in any medium, provided the original work is properly cited.

\begin{abstract}
The effect of lubricating oil on the morphology of particulate matter (PM) was studied in a diesel engine fueled with pure diesel fuel and blended fuel containing $0.5 \%$ by weight of lubricating oil. Particulate matter emitted by diesel engines is formed primarily by soot agglomerates which are composed of primary particles. In this paper, particulate matter was collected with a thermophoretic sampling system, and a high-resolution transmission electron microscope (TEM) was used to investigate the primary particles. A Fast Particulate Spectrometer, DMS 500, was used to determine the particle size distributions. The TEM results indicated that the mean diameters of the primary particles increased after the oil was added into the fuel. Particle size distributions results showed that lubricating oil in the fuel gave rise to a higher concentration in nucleation mode.
\end{abstract}

\section{Introduction}

Although diesel engines are widely used in on-road transport because of their efficiency and reliability, particulate matter (PM) emitted from diesel engines has negative impacts on human health $[1,2]$. The total mass of PM emissions from diesel engines has been significantly reduced with the advent of stricter emission standards. However, the current emission standards impose limitations only on the mass of particulate matter that is larger than $2.5 \mu \mathrm{m}$ (PM 2.5). Although smaller particulates contribute little to the total mass, their significant number and effect on human health and the environment have drawn people's attention. This is also the reason why particulate matter smaller than $2.5 \mu \mathrm{m}$ is proposed to be included in future emission limits. To achieve lower PM emissions, regardless of total mass or number, the optimization of combustion and the use of a posttreatment system could be effective ways to deal with this issue. Detailed characteristics of PM are indispensable to achieve the desired improvement.

A commercial mobility sizer and high-resolution transmission electron microscope (TEM) are widely used in investigating the detailed characteristics of PM. Although the use of a mobility sizer is always considered to be a controversial way to determine PM characteristics, its high speed and stability are indisputable, especially in comparing PM emissions; thus it is widely used in PM investigations [37]. The results from the mobility sizer were also verified to be consistent in tendency with that from TEM investigations [8].

Of course, results from TEM images are more direct and visual. Coupled with a thermophoretic sampling system, many detailed characteristics of PM, such as the primary particle diameters, morphology, and gyration diameters and others, can be achieved [9-13]. These results are of great importance in understanding the formation of particulate matter and in guiding the optimization of combustion to achieve lower PM emissions. However, the choice of samples and the conversion from pixels to actual dimensions can lead to tiny errors.

Many factors will influence the formation of PM and lubricating oil is an important one [14-23]. During engine operation, lubricating oil consumption is inevitable and this is the reason why PM emissions were found in a hydrogenpowered engine [24]. 


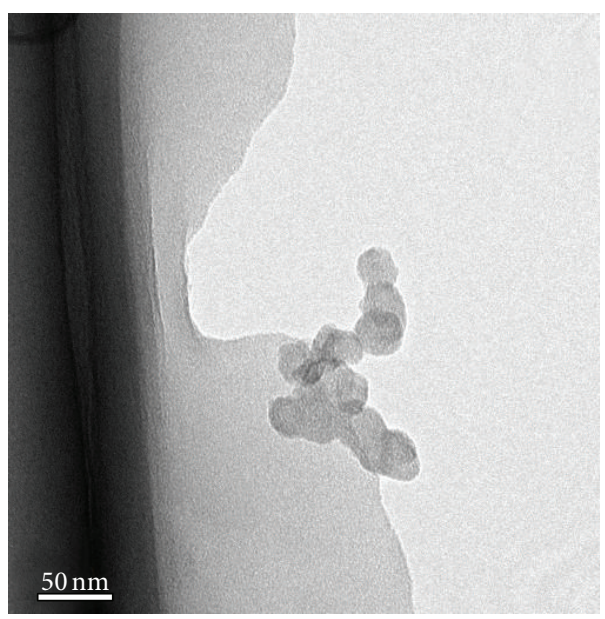

(a)

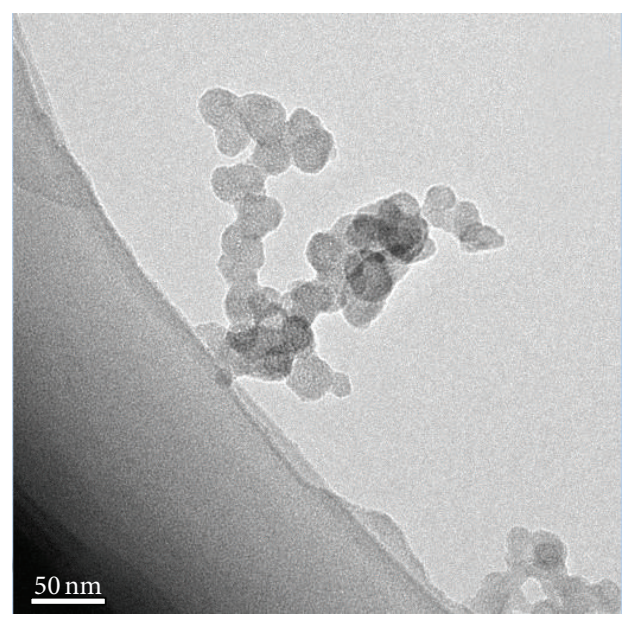

(b)

FIGURE 1: TEM photographs of diesel particulates sampled at (a) $2000 \mathrm{rpm} / 25 \%$ load when fueled with pure diesel and (b) $2000 \mathrm{rpm} / 75 \%$ load when fueled with blended fuel containing oil.

The contribution of lubricating oil to PM formation is focused primarily on soluble organic fraction (SOF) [25] and soot [26]. Lubricating oil shows great influence on SOF formation and this can be explained through its means of consumption. The means by which lubricating oil is consumed has been investigated in detail [27]. Such investigations have concluded that cylinder liner evaporation substantially affects total engine oil consumption.

It is easy for the oil evaporated from the cylinder liner to condense on the soot surface and contribute to SOF formation. Part of the oil entering the combustion chamber is not burnt and will contribute to the SOF formation in the same way.

When considering the contributors to oil consumption, part of the oil which enters the combustion chamber will be involved with the fuel combustion because of the complex airflow motion in the chamber. It is easy to imagine that combustion of fuel will be influenced to a minor extent because of lubricating oil droplets cracking, evaporating, or combusting. Oil droplets will absorb heat from their surroundings when they crack or evaporate, and the resultant lower temperature will favor PM formation. Previous studies have also indicated that use of lubricating oil will lead to the change of particle size distributions and total number of concentrations [28].

The main purpose of this paper is to investigate the influence of lubricating oil combustion on soot formation in a diesel engine. Because of the low rate of oil consumption during normal engine operation, it is difficult to achieve repetitive and reliable results. Although oil consumption will rise when engine speed and load increases [27], yet different operating conditions will influence PM formation. In this paper, $0.5 \%$ oil in weight is blended into the diesel fuel. This does not conform to normal operating conditions but does make sense in investigating the influence of oil combustion on PM formation. Particulate matter was collected with a thermophoretic sampling system, and a highresolution transmission electron microscope (TEM) was used to investigate the primary particles. A Fast Particulate Spectrometer, DMS 500, was used to determine the particle size distributions. The results can well illustrate the influence of lubricating oil combustion on PM formation.

\section{Experimental Setup}

The experiments were performed on a direct-injection fourstroke diesel engine (Yunnei 4100QB) with a peak torque of $340 \mathrm{Nm}$ at $2000 \mathrm{rpm}$. The compression ratio of each cylinder is 17.8 to 1 and the displacement volume is $3.612 \mathrm{~L}$. The engine speed in this paper was $2000 \mathrm{rpm}$ and the load was $25 \%$ and $75 \%$ of full load. The test fuel is pure diesel fuel and blended fuel containing $0.5 \%$ by weight of lubricating oil (Mobil API CI-4 15W40). The oil blended into the diesel fuel was the same as that in the oil pan.

Before the test, the engine and the DMS500 were warmed up for half an hour. A widely used thermophoretic sampling system was employed to collect the particulate matter. Copper grids were used during the sampling. After each sampling, the grid was carefully removed and stored in the sample box until the TEM observation. A JEM-2010FEF transmission electron microscope with a resolution of $0.23 \mathrm{~nm}$ was used to observe particles. Magnifications above 42,500x were used for spherule diameter measurements.

After each sampling, the engine was kept operating. The valve leading to the DMS500 was opened. The pipe connecting the DMS500 to the exhaust pipe was at almost the same position where particles were sampled for TEM observation. The DMS500 would adjust the dilution ratio automatically, and the data would be steady after about 10 seconds. After about 30 seconds, when the data was steady, the experimental results were recorded for 15 seconds.

\section{Results and Discussions}

Figures 1(a) and 1(b) show the typical TEM images of diesel particulates sampled at $2000 \mathrm{rpm} / 25 \%$ load when fueled with 


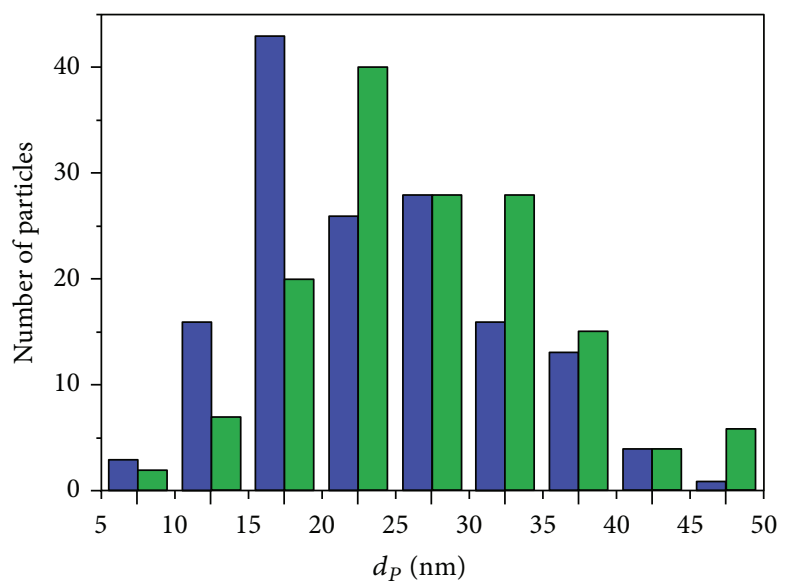

Measurements: 150

Engine speed: $2000 \mathrm{rpm}$

$25 \%$ load

Mean diameter $23.63 \mathrm{~nm}$

Standard deviation $8.20 \mathrm{~nm}$

$75 \%$ load

Mean diameter $27.21 \mathrm{~nm}$

Standard deviation $9.06 \mathrm{~nm}$

Figure 2: Primary particle diameter distribution when fueled with pure diesel.

pure diesel and at $2000 \mathrm{rpm} / 75 \%$ load when fueled with blended fuel containing oil, respectively.

It can be seen from Figure 1 that the appearance of particulates is almost identical to those in other studies; that is, particulates have different shapes with grapelike structures and many spherical primary particles collect to form clusters.

3.1. Primary Particle Size Distributions. 20 images were taken of each operating condition and 7 or 8 primary particles with clear boundaries were selected for measurement. Mean diameters of primary particles are obtained by averaging the diameters of 150 primary particles. From the resulting primary diameters, size distributions were obtained for each operating condition as shown in Figures 2 and 3.

Clear conclusions can be made that the distributions were statistically normal before and after the oil is added into diesel fuel. It is statistically acceptable to choose 150 primary particles. In fact, 50 primary particles can well reflect the distributions of particles [9].

The influences of lubricating oil on the primary particle formations are listed below by analyzing the results shown in Figures 2 and 3 .

First, the mean primary particle diameters are about $23 \mathrm{~nm}, 27 \mathrm{~nm}, 27 \mathrm{~nm}$, and $28 \mathrm{~nm}$ under four different conditions as shown in Figures 2 and 3. Uncertainties will definitely exist during the diameter measuring but errors should be within $1 \mathrm{~nm}$. Results in this paper are well in accordance with past results $[29,30]$. Although different engines were used in these experiments, the mean diameters of primary particles were in the range of $19 \mathrm{~nm}$ to $35 \mathrm{~nm}$. The results indicated that engine types or operating conditions may show little influence on primary particle formation and that the PM emissions should be influenced significantly by soot oxidation.

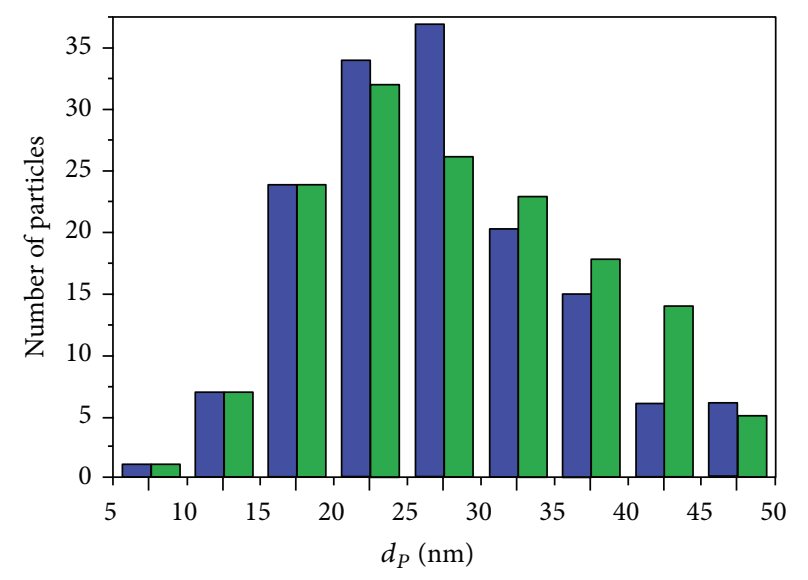

Measurements: 150

Engine speed: $2000 \mathrm{rpm}$ $25 \%$ load

Mean diameter $27.32 \mathrm{~nm}$ Standard deviation $8.76 \mathrm{~nm}$
$75 \%$ load

Mean diameter $28.46 \mathrm{~nm}$ Standard deviation $9.10 \mathrm{~nm}$
Figure 3: Primary particle diameter distribution when fueled with blended fuel containing oil.

However, although primary particle diameter distributions were typically normal ones, problems still exist when judging the primary particle diameters. Figure 4 shows the typical TEM images of diesel particulates sampled at $2000 \mathrm{rpm} / 25 \%$ load when fueled with pure diesel.

Primary particle diameters in the four parts of Figure 4 are quite different: $15 \sim 20 \mathrm{~nm}, 25 \sim 30 \mathrm{~nm}, 35 \sim 40 \mathrm{~nm}$, and 10 $30 \mathrm{~nm}$, respectively. This phenomenon indicates that combustion in the chamber is not homogeneous. Meanwhile, diameters of primary particles in one cluster tended to be the same, which means that primary particles may agglomerate immediately after they are formed.

During the actual sampling and testing, the diameter of the copper grid is about $3 \mathrm{~mm}$, and the range of TEM observation is an extremely small part of the grid. Choice of cluster photographs may be another factor that causes errors.

Second, the mean diameters of primary particles decrease when the load increases. This can be explained by the situation whereby as combustion temperature and exhaust temperature increase with an increased load, particles are oxidized more completely. However, high load requires more fuel to be injected into the combustion chamber and then incomplete combustion will lead to the growth of particle formation. Other investigations have also explained the conflicting process of particle formation [11,31]. In this paper, the oxidation rates of particles exceeded the surface growth rates so that primary particles decreased with the load increasing.

Third, mean diameters of primary particle increase from $23.63 \mathrm{~nm}$ to $27.21 \mathrm{~nm}$ at a speed of $2000 \mathrm{rpm} / 25 \%$ and from $27.32 \mathrm{~nm}$ to $28.46 \mathrm{~nm}$ at a speed of $2000 \mathrm{rpm} / 75 \%$ load. The results indicate that mean diameters increase after the oil is added into the diesel fuel and the effect is more pronounced when the load is lower. It can be explained that particles will form when the oil is burnt. Since the lubricating oil 


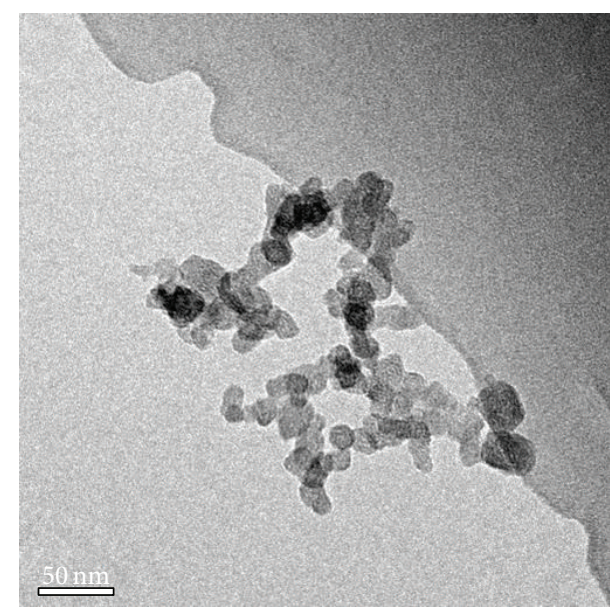

(a)

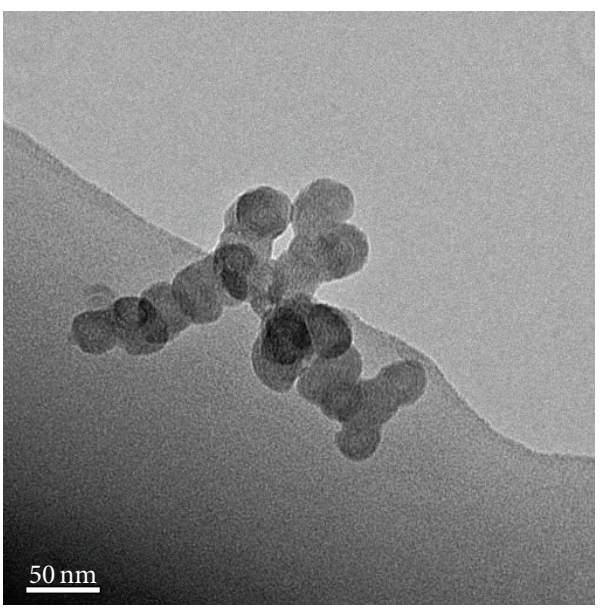

(c)

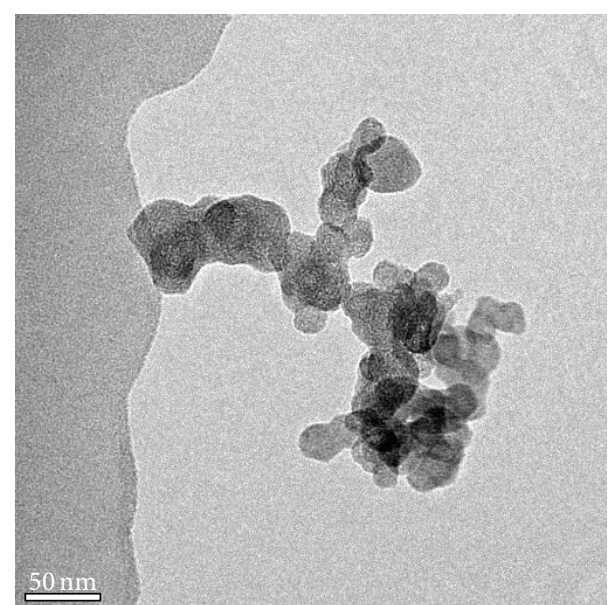

(b)

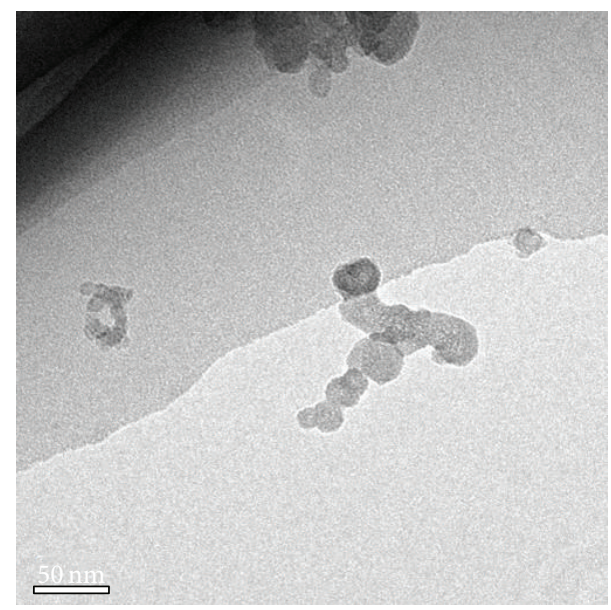

(d)

FIGURE 4: TEM photographs of diesel particulates sampled at $2000 \mathrm{rpm} / 25 \%$ load when fueled with pure diesel.

is composed primarily of macromolecules, the particles are bigger than those formed during the combustion of diesel fuel at low load. Combustion temperature will rise when the load is higher and the contribution is diminished. During the actual engine operation, combustion of lubricating oil should contribute little to the total PM emissions because of the low oil consumption. Another factor is the influence of lubricating oil droplets on particle formation during the combustion of diesel fuel. In a small range surrounding the lubricating oil droplets, combustion temperature will change because of the different physical and chemical characteristics of lubricating oil. In addition, additives in the oil may also influence the formation or oxidation of particles. When the load is high, more oil is injected into the combustion chamber and more particles form and then the influence of lubricating oil is not that obvious.

3.2. Particle Size Distributions. Particle size distributions at different operating conditions are shown in Figures 5 and 6.
The mean diameter of the agglomerated particles (accumulation mode) is in the range of 50-100 $\mathrm{nm}$.

Particle size distributions changed significantly after the oil is blended into diesel fuel. The most obvious change is in the nucleation mode. When fueled with pure diesel, there are two peaks in nucleation mode and the peak increases rapidly after the oil is blended, regardless of low load or high load. Peaks in accumulation mode changed little after the oil is blended. A conclusion can also be made that oil exerts less influence on the particle size distributions at higher load.

Figure 7 shows the total number concentrations under different conditions. It can be seen here that the total number concentrations increase after the oil is blended into diesel fuel. The influence of lubricating oil on PM emissions is significant when the load is low. Oil shows little influence on total number concentration when the load is high and these results agree well with that of primary particle diameters. However, the total number concentrations are almost the same when the oil is added into diesel fuel. It can be explained that the oil has great influence on the characteristic of particles and 


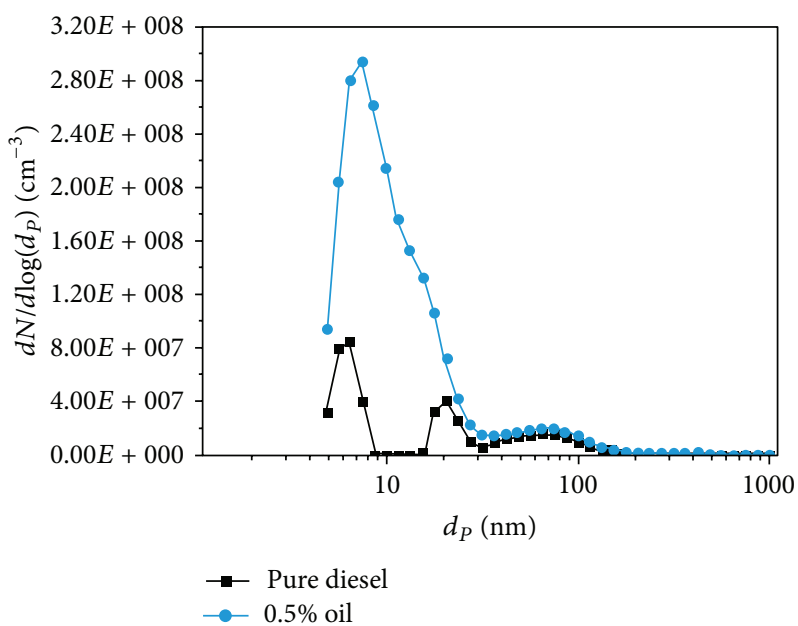

Figure 5: Particle size distributions at the speed of $2000 \mathrm{rpm} / 25 \%$ load.

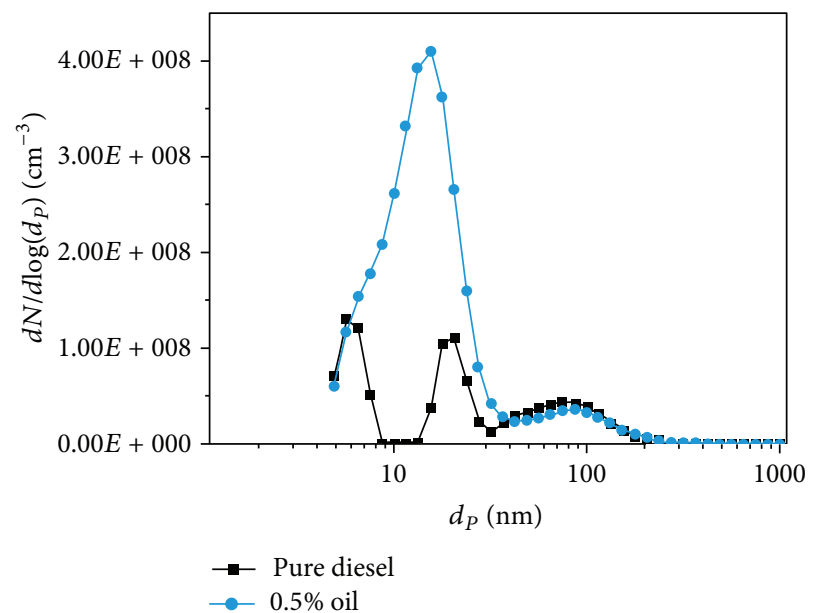

FIgURE 6: Particle size distributions at the speed of $2000 \mathrm{rpm} / 75 \%$ load.

TABLE 1: Particles formation comparison.

\begin{tabular}{lccc}
\hline & Load & $25 \%$ & $75 \%$ \\
\hline Pure diesel & $\begin{array}{c}\text { Primary particle } \\
\text { diameter } \\
\text { Total number } \\
\text { concentrations }\end{array}$ & $23.63 \mathrm{~nm}$ & $27.21 \mathrm{~nm}$ \\
& $\begin{array}{c}\text { Primary particle } \\
\text { diameter }\end{array}$ & $27.32 e^{7}$ & $1.21 e^{8}$ \\
\hline $\begin{array}{l}\text { Diesel } \\
\text { blended with } \\
\text { oil }\end{array}$ & $\begin{array}{c}\text { Total number } \\
\text { concentrations }\end{array}$ & $1.91 e^{8}$ & $28.46 \mathrm{~nm}$ \\
\hline
\end{tabular}

this leads to the change of the spectrum identification of the DMS500.

Table 1 shows the comparison of particles formation.

\section{Conclusions}

(1) Lubricating oil involved in fuel combustion will lead to an increase in primary particle diameters and the influence is obvious when the load is low.

(2) Particle size distribution results also indicate that the influence of lubricating oil on PM emissions is less obvious when the load is high.

(3) Results from the mobility sizer and TEM observation show the approximate tendency in comparing the PM emissions. Microstructures of particles will change after oil is involved in combustion.

\section{Conflict of Interests}

The authors declare that there is no conflict of interests regarding the publication of this paper. 


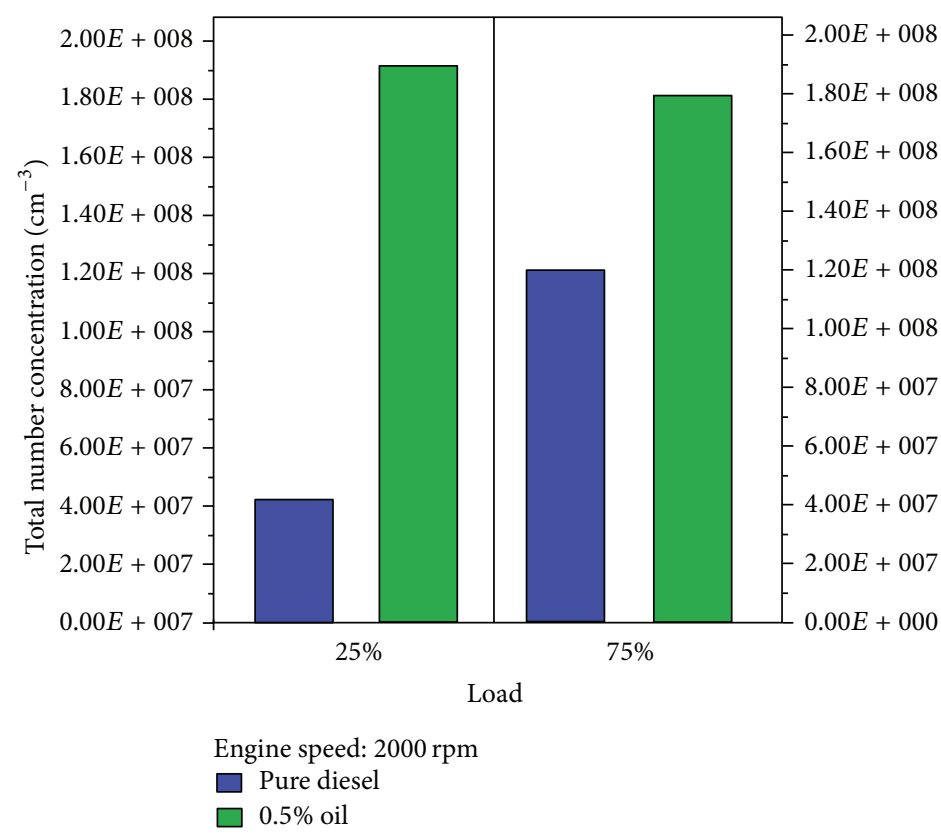

FIgURE 7: Total number concentrations under different conditions.

\section{Acknowledgments}

Authors wish to express their sincere appreciation to the financial support of the NSFC (51376136) and NSFC (51406132).

\section{References}

[1] A. D. Kappos, P. Bruckmann, T. Eikmann et al., "Health effects of particles in ambient air," International Journal of Hygiene and Environmental Health, vol. 207, no. 4, pp. 399-407, 2004.

[2] D. B. Warheit, C. M. Sayes, K. L. Reed, and K. A. Swain, "Health effects related to nanoparticle exposures: environmental, health and safety considerations for assessing hazards and risks," Pharmacology and Therapeutics, vol. 120, no. 1, pp. 35-42, 2008.

[3] H. Kim and B. Choi, "Effect of ethanol-diesel blend fuels on emission and particle size distribution in a common-rail direct injection diesel engine with warm-up catalytic converter," Renewable Energy, vol. 33, no. 10, pp. 2222-2228, 2008.

[4] B. Bougie, L. C. Ganippa, A. P. van Vliet, W. L. Meerts, N. J. Dam, and J. J. T. Meulen, "Soot particulate size characterization in a heavy-duty diesel engine for different engine loads by laserinduced incandescence," Proceedings of the Combustion Institute, vol. 31, pp. 685-691, 2007.

[5] T. Gupta, A. Kothari, D. K. Srivastava, and A. K. Agarwal, "Measurement of number and size distribution of particles emitted from a mid-sized transportation multipoint port fuel injection gasoline engine," Fuel, vol. 89, no. 9, pp. 2230-2233, 2010.

[6] C. Wang, H. Xu, J. M. Herreros, and J. Wang, "Impact of fuel and injection system on particle emissions from a GDI engine," Applied Energy, vol. 132, pp. 178-191, 2014.

[7] P.-Q. Tan, S.-S. Ruan, Z.-Y. Hu, D.-M. Lou, and H. Li, "Particle number emissions from a light-duty diesel engine with biodiesel fuels under transient-state operating conditions," Applied Energy, vol. 113, pp. 22-31, 2014.

[8] M. F. Chandler, Y. Teng, and U. O. Koylu, "Diesel engine particulate emissions: a comparison of mobility and microscopy size measurements," Proceedings of the Combustion Institute, vol. 31, pp. 2971-2979, 2007.

[9] M. Lapuerta, F. J. Martos, and J. M. Herreros, "Effect of engine operating conditions on the size of primary particles composing diesel soot agglomerates," Journal of Aerosol Science, vol. 38, no. 4, pp. 455-466, 2007.

[10] A. Neer and U. O. Koylu, "Effect of operating conditions on the size, morphology, and concentration of submicrometer particulates emitted from a diesel engine," Combustion and Flame, vol. 146, no. 1-2, pp. 142-154, 2006.

[11] J. Zhu, K. O. Lee, A. Yozgatligil, and M. Y. Choi, "Effects of engine operating conditions on morphology, microstructure, and fractal geometry of light-duty diesel engine particulates," Proceedings of the Combustion Institute, vol. 30, pp. 2781-2789, 2005.

[12] K. Tian, K. A. Thomson, F. Liu, D. R. Snelling, G. J. Smallwood, and D. Wang, "Determination of the morphology of soot aggregates using the relative optical density method for the analysis of TEM images," Combustion and Flame, vol. 144, no. 4, pp. 782-791, 2006.

[13] Y. Wei, K. Wang, W. Wang et al., "Comparison study on the emission characteristics of diesel- and dimethyl ether-originated particulate matters," Applied Energy, vol. 130, pp. 357-369, 2014.

[14] M. T. Spencer, L. G. Shields, D. A. Sodeman, S. M. Toner, and K. A. Prather, "Comparison of oil and fuel particle chemical signatures with particle emissions from heavy and light duty vehicles," Atmospheric Environment, vol. 40, no. 27, pp. 52245235,2006 
[15] J. Cromas and J. B. Ghandhi, "Lubricating oil contribution to direct-injection two stroke engine particulate emissions," SAE Technical Paper 2004-32-0012, 2004.

[16] J. Czerwinski, J. L. Pétermann, A. Ulrich, G. Mueller, and A. Wichser, "Particle emissions of a TDI-engine with different lubrication oils," SAE Paper 2005-01-1100, 2005.

[17] B. A. Buchholz, R. W. Dibble, D. Rich, and A. S. Cheng, "Quantifying the contribution of lubrication oil carbon to particulate emissions from a diesel engine," SAE Paper 200301-1987, SAE International, 2003.

[18] H. Jung, D. B. Kittelson, and M. R. Zachariah, "The influence of engine lubricating oil on diesel nanoparticle emissions and kinetics of oxidation," SAE Paper 2003-01-3179, 2003.

[19] R. Gligorijevic, J. Jevtic, and D. J. Borak, "Engine oil contribution to diesel exhaust emissions," Journal of Synthetic Lubrication, vol. 23, no. 1, pp. 27-38, 2006.

[20] K. Froelund, E. C. Owens, E. Frame et al., "Impact of lubricant oil on regulated emissions of a light-duty Mercedes-Benz OM611 CIDI-engine," SAE Paper 2001-01-1901, 2001.

[21] P. C. C. de Albuquerque, R. N. de Andrade Ávila, P. H. Barros Zárante, and J. R. Sodré, "Lubricating oil influence on exhaust hydrocarbon emissions from a gasoline fueled engine," Tribology International, vol. 44, no. 12, pp. 1796-1799, 2011.

[22] K. M. Jefferd, J. S. Rogerson, D. E. Copp, R. L. Brundle, and M. A. Huntly, "The impact of lubricants on heavy duty diesel engine fuel economy and exhaust emissions," SAE Paper 2000-01-1983, 2000.

[23] G. W. R. Taylor, “The effect of lubricating oil volatility on diesel emissions," SAE Paper 2001-01-1261, 2001.

[24] A. L. Miller, C. B. Stipe, M. C. Habjan, and G. G. Ahlstrand, "Role of lubrication oil in particulate emissions from a hydrogen-powered internal combustion engine," Environmental Science and Technology, vol. 41, no. 19, pp. 6828-6835, 2007.

[25] S. Brandenberger, M. Mohr, K. Grob, and H. P. Neukom, "Contribution of unburned lubricating oil and diesel fuel to particulate emission from passenger cars," Atmospheric Environment, vol. 39, no. 37, pp. 6985-6994, 2005.

[26] M. S. P. Kahandawala, J. L. Graham, and S. S. Sidhu, "Impact of lubricating oil on particulates formed during combustion of diesel fuel-a shock tube study," Fuel, vol. 83, no. 13, pp. 18291835, 2004.

[27] E. Yilmaz, T. Tian, V. W. Wong, and J. B. Heywood, "The contribution of different oil consumption sources to total oil consumption in a spark ignition engine," SAE Paper 2004-012909, 2004.

[28] L. Dong, G. Shu, and X. Liang, "Effect of lubricating oil on the particle size distribution and total number concentration in a diesel engine," Fuel Processing Technology, vol. 109, pp. 78-83, 2013.

[29] M. Wentzel, H. Gorzawski, K.-H. Naumann, H. Saathoff, and S. Weinbruch, "Transmission electron microscopical and aerosol dynamical characterization of soot aerosols," Journal of Aerosol Science, vol. 34, no. 10, pp. 1347-1370, 2003.

[30] K. Park, D. B. Kittelson, and P. H. McMurry, "Structural properties of diesel exhaust particles measured by Transmission Electron Microscopy (TEM): relationships to particle mass and mobility," Aerosol Science and Technology, vol. 38, no. 9, pp. 881889, 2004.

[31] K. O. Lee, R. Cole, R. Sekar et al., "Detailed characterization of morphology and dimensions of diesel particulates via thermophoretic sampling," SAE Technical Paper 2001-01-3572, 2001. 

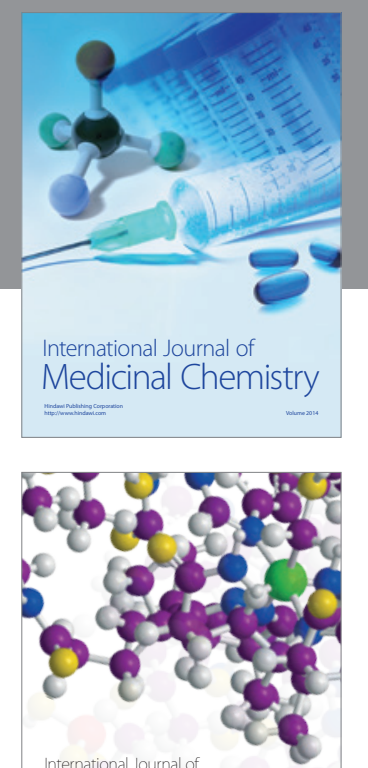

\section{Carbohydrate} Chemistry

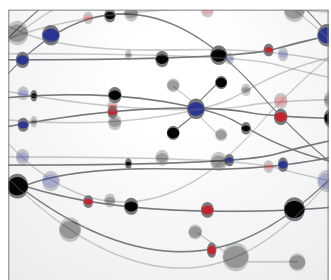

The Scientific World Journal
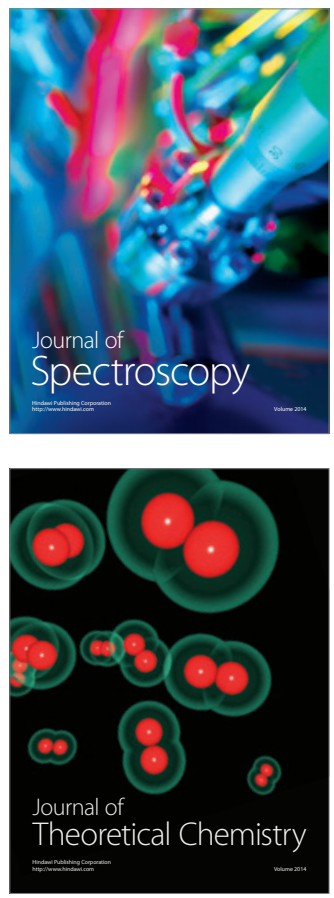
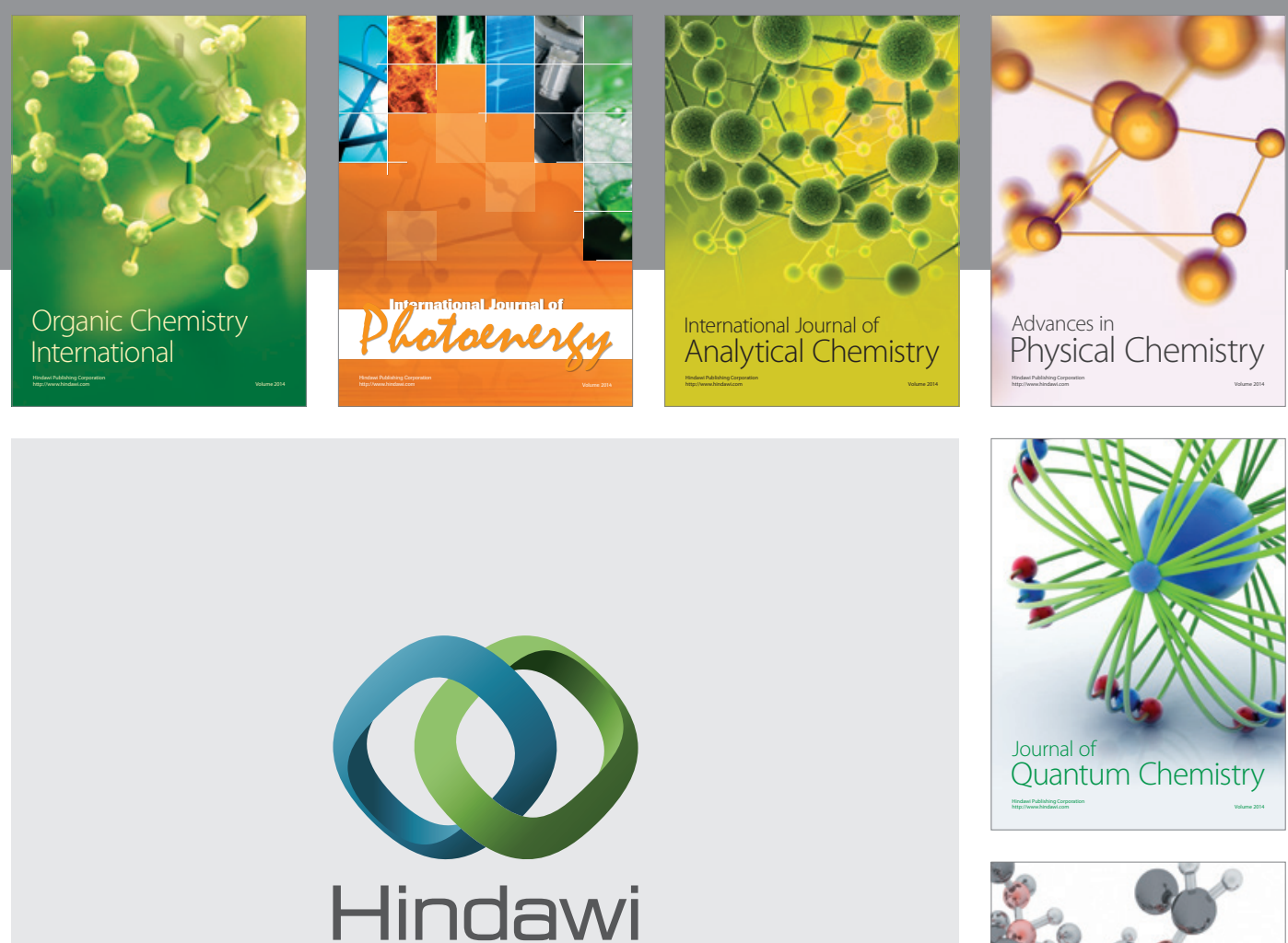

Submit your manuscripts at

http://www.hindawi.com

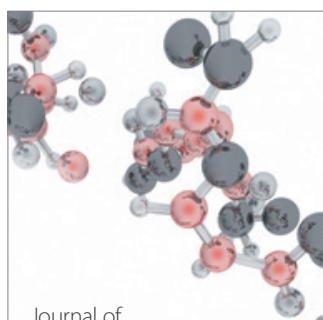

Analytical Methods

in Chemistry

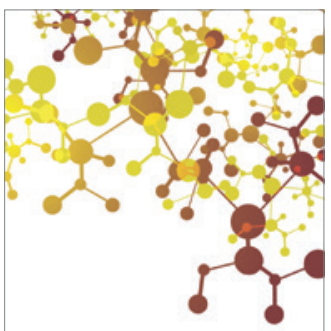

Journal of

Applied Chemistry

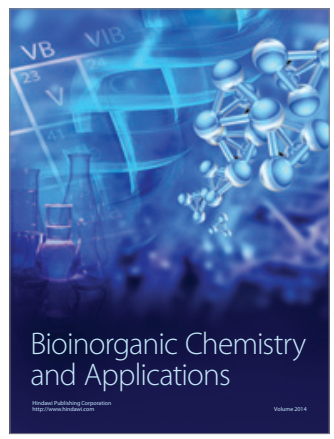

Inorganic Chemistry
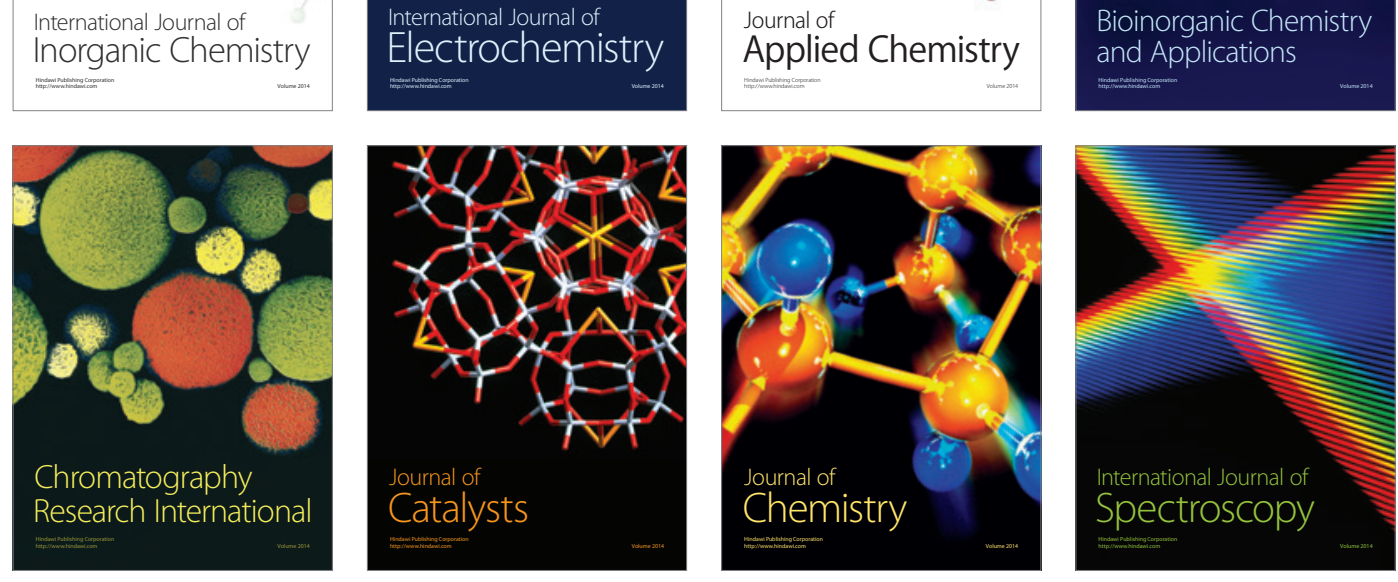